\title{
ACOX1, regulated by C/EBP $\alpha$ and miR-25-3p, promotes bovine preadipocyte adipogenesis
}

\author{
Feng Zhang, Qi Xiong, Hu Tao, Yang Liu, Nian Zhang, Xiao-Feng Li, Xiao-Jun Suo, Qian-Ping Yang and Ming-Xin Chen \\ Hubei Key Laboratory of Animal Embryo Engineering and Molecular Breeding, Institute of Animal Husbandry and Veterinary, Hubei Academy of \\ Agricultural Sciences, Wuhan, China
}

Correspondence should be addressed to M-X Chen: chenmingxin18@163.com

\begin{abstract}
Acyl-coenzyme A oxidase 1 (ACOX1) is the first and rate-limiting enzyme in peroxisomal fatty acid $\beta$-oxidation of fatty acids. Previous studies have reported that ACOX1 was correlated with the meat quality of livestock, while the role of ACOX1 in intramuscular adipogenesis of beef cattle and its transcriptional and post-transcriptional regulatory mechanisms remain unclear. In the present study, gain-of-function and loss-of-function assays demonstrated that $A C O X 1$ positively regulated the adipogenesis of bovine intramuscular preadipocytes. The C/EBP $\alpha$-binding sites in the bovine ACOX1 promoter region at -1142 to $-1129 \mathrm{bp},-831$ to $-826 \mathrm{bp}$, and -303 to $-298 \mathrm{bp}$ were identified by promoter deletion analysis and site-directed mutagenesis. Electrophoretic mobility shift assays (EMSA) and chromatin immunoprecipitation (ChIP) further showed that these three regions are $\mathrm{C} / \mathrm{EBP} \alpha$-binding sites, both in vitro and in vivo, indicating that $\mathrm{C} / \mathrm{EBP} \alpha$ directly interacts with the bovine ACOX1 promoter and inhibits its transcription. Furthermore, the results from bioinformatics analysis, dual luciferase assay, site-directed mutagenesis, qRT-PCR, and Western blotting demonstrated that miR-25-3p directly targeted the ACOX1 3'UTR (3'UTR). Taken together, our findings suggest that ACOX1, regulated by transcription factor $\mathrm{C} / \mathrm{EBP} \alpha$ and $\mathrm{miR}-25-3 \mathrm{p}$, promotes adipogenesis of bovine intramuscular preadipocytes via regulating peroxisomal fatty acid $\beta$-oxidation.
\end{abstract}

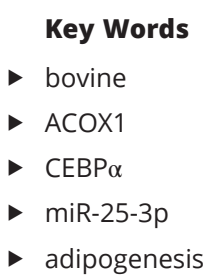

Journal of Molecular Endocrinology (2021) 66, 195-205

\section{Introduction}

Acyl-coenzyme A oxidase (ACOX) and mitochondrial acyl-CoA dehydrogenase belong to the same flavoenzyme superfamily and have evolved from the same progenitor (Kunau et al. 1995). ACOX1 is the first and rate-limiting enzyme in peroxisomal fatty acid $\beta$-oxidation of fatty acids of all eukaryotes: acyl-CoAs longer than C8 were desaturated to 2-trans-enoyl-CoAs, donating electrons directly to molecular oxygen, thus generating $\mathrm{H}_{2} \mathrm{O}_{2}$ and energy, lost as heat ( $\mathrm{Li}$ et al. 2000, Morais et al. 2007). ACOX1 is a highly conserved enzyme with a unique expression pattern, its mRNA and protein expression were most abundant in liver, followed by kidney, brain and adipose tissue (Nohammer et al. 2000).
Previous studies have reported that ACOX1 plays an important role in lipid metabolism. Inhibition of ACOX1 was a novel and effective approach for the treatment of high-fat diet or obesity induced metabolic diseases by improving mitochondrial lipid and reactive oxygen species (ROS) metabolism (Zeng et al. 2017). The down-expression of PPAR $\alpha$ and ACOX1 in liver of rats with alcoholic fatty liver disease suppressed fatty acid metabolism and leaded to triglyceride (TG) deposition in the liver (Tong et al. 2016). siRNA knockdown of ACOX1 strongly increased the levels of very long chain fatty acids (VLCFA) and neutral lipids (Baarine et al. 2012).

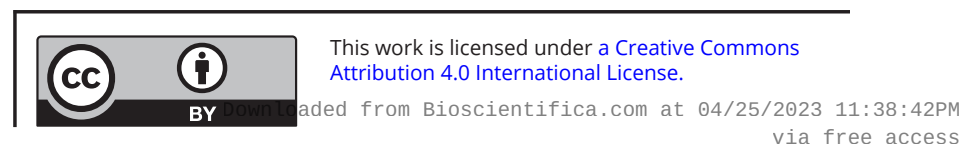


Besides, several studies have found that ACOX1 was correlated with the meat quality of livestock. Phenotype analysis of 334 Large White $\times$ Meishan $\mathrm{F}_{2}$ pigs showed that Pst I variants of ACOX1 gene significantly affected the meat color value and meat marble score of both longissimus dorsi and biceps femoris (Zuo et al. 2007). Porcine ACOX1 gene was most closely linked to significant quantitative trait loci (QTL) affecting average daily gain, birth weight, backfat thickness, and fatty acid composition (Casas Carrillo et al. 1997, Clop et al. 2003, Yue et al. 2003). A SNP in exon 13 of bovine ACOX1 gene resulted in significant differences in backfat thickness and meat marble score among genotypes (Jiao et al. 2011). The g.224G > A SNP located in ACOX1 coding regions was significantly associated with meat quantity grade at slaughter and backfat thickness tended to be greater in Korean cattle (Lee et al. 2010). However, to our knowledge, the role of $A C O X 1$ in intramuscular adipogenesis of beef cattle has not been reported, and its transcriptional and post-transcriptional regulatory mechanisms are not clear.

Thus, in this study, we first investigated the role of ACOX1 in adipogenesis by gain-of-function and loss-offunction assays. Then, the promoter of bovine ACOX1 was identified, and the binding sites of the transcription factor CCAAT enhancer-binding proteins alpha $(\mathrm{C} / \mathrm{EBP} \alpha)$, which is a critical transcription factors in fat deposition and adipocyte differentiation, were predicted and verified using bioinformatics software and experiments; And, the transcriptional activity of $A C O X 1$ was depressed by $\mathrm{C} / \mathrm{EBP} \alpha$. Finally, the targeted site of miR-25-3p in bovine ACOX1 3' UTR was predicted and verified, and the posttranscriptional activity of $A C O X 1$ was depressed by miR-25-3p.

\section{Materials and methods}

\section{Bovine intramuscular preadipocytes isolation}

Dabieshan yellow cattles (24-30 months old, male) were provided by Hubei Hegen Agricultural Technology Ltd and harvested at a local abattoir using standard procedures. Bovine intramuscular preadipocytes were isolated from longissimus dorsi muscle, the method was as follows. The longissimus dorsi muscle was washed five times with PBS containing 5\% penicillin/streptomycin and transported to laboratory in PBS. The following procedures were conducted in a sterile field. Adipose tissues were separated from muscle bundles and finely chopped into $1-\mathrm{mm}^{3}$ pieces with scissors in PBS and then incubated with $0.1 \%$ collagenase type I (Sigma) for $1 \mathrm{~h}$ at $37^{\circ} \mathrm{C}$ with mixing every $10 \mathrm{~min}$. After enzymatic digestion, the released fat stromal cells were suspended in DMEM (Gibco) supplemented with 15\% fetal bovine serum (FBS; Gibco), and the suspension was filtered through a $100 \mu \mathrm{m}$ filter (Corning Incorporated). Then, the cells were collected by centrifugation at $650 \mathrm{~g}$ for $5 \mathrm{~min}$. The cells were added to fresh DMEM supplemented with 15\% FBS and 1\% penicillin/streptomycin. The cells were then plated in nunclon flasks and cultured in an atmosphere of $5 \% \mathrm{CO}_{2}$ at $37^{\circ} \mathrm{C}$. After $12 \mathrm{~h}$, the non-adherent cells were removed. When cells achieved $80 \%$ to $90 \%$ confluence, they were passaged by trypsinisation.

\section{Differentiation induction and oil red 0 staining}

For evaluating the effect of $A C O X 1$ on adipogenic differentiation of bovine intramuscular preadipocytes, bovine intramuscular preadipocytes were seeded in 6-well plates the day before transfection. pCDNA-ACOX1, pCDNA-3.1(+), Si-ACOX1 and negative control (NC) were transfected into confluent ( $80 \%$ ) cells, respectively. After $24 \mathrm{~h}$, adipogenic differentiation of bovine intramuscular preadipocytes were induced in a medium comprising DMEM supplemented with 10\% FBS, 0.5 mM 3-isobutyl1-methylxanthine, $1 \mu \mathrm{M}$ dexamethasone, and $10 \mu \mathrm{g} / \mathrm{mL}$ of insulin (both from Sigma) for 2 days (from day 0 to day 2). The medium was then replaced with $10 \mu \mathrm{g} / \mathrm{mL}$ insulin in 10\% FBS supplemented medium for an additional 2 days (from day 2 to day 4). Lastly, the medium was replaced with 10\% FBS supplemented medium (from day 4 to day 8$)$.

On day 8, medium was discarded and cells were washed twice with PBS, fixed in 4\% paraformaldehyde for 0.5-1 $\mathrm{h}$ and washed again with PBS. The cells were then stained with Oil Red O (0.5 g Oil Red O; Sigma) in 100 $\mathrm{mL}$ isopropanol diluted with water (60:40) for $1 \mathrm{~h}$. After being stained, the cells were washed twice in PBS and then photographed. The lipid accumulation of stained cells was qualified by measuring its absorbance at the wavelength of $550 \mathrm{~nm}\left(\mathrm{OD}_{550}\right)$.

\section{Triglyceride content, ATP, and ROS assays}

For detecting the concentrations of triglyceride, ATP, and ROS, bovine intramuscular preadipocytes were seeded in 24-well plates the day before transfection. pCDNA-ACOX1, pCDNA-3.1(+), Si-ACOX1 and NC were transfected into confluent $(\sim 80 \%)$ cells, respectively. After 24-48 h, the concentrations of triglyceride and ATP in the lysates of cells were measured with

This work is licensed under a Creative Commons Attribution 4.0 International License. ded from Bioscientifica.com at 04/25/2023 11:38:42PM 
commercial kits (Applygen (Beijing, China) and Beyotime (Shanghai, China), respectively) following the manufacturer's instructions, and normalized to the protein content ( $\mu \mathrm{mol} / \mathrm{mg}$ protein) using the BCA assay kit (Thermo Scientific). ROS were measured using the reactive oxygen species assay kit (Beyotime) following the manufacturer's protocol.

\section{RNA isolation and qRT-PCR}

For quantifying the mRNA expression of genes, cells were seeded in six-well plates. After $48 \mathrm{~h}$ of the transfection, cells were harvested and total RNA was isolated using a HP Total RNA Kit (Omega, Norcross, GA, USA) according to the manufacturer's protocol. The cDNA was synthesized using a PrimeScript TM RT reagent Kit with gDNA Eraser (Takara) according to the manufacturer's protocol. The qRT-PCR was performed in triplicate with iQSYBR green Supermix (Bio-Rad) in a LightCycler480 Realtime PCR machine (Roche). The mRNA levels of target genes were reported relative to those of the house keeping gene $\beta$-actin by using the $2^{-\Delta \Delta C t}$ method. The qRT-PCR primers are listed in Supplementary Table 1 (see section on supplementary materials given at the end of this article).

\section{Protein isolation and Western blotting}

For detecting the protein expression of genes, cells were seeded in 6-well plates. After $48 \mathrm{~h}$ of the transfection, cells were harvested and total protein was isolated using RIPA Lysis Buffer (Beyotime). The cells were washed briefly with cold PBS $\left(4^{\circ} \mathrm{C}\right), 150 \mu \mathrm{L}$ RIPA Lysis Buffer (containing $1 \mathrm{mM}$ PMSF) was added, incubated for $1 \mathrm{~min}$ at room temperature, and then centrifuged at $12,000 \boldsymbol{g}$ for $5 \mathrm{~min}$. The supernatant extract was used for Western blot analysis.

Protein concentrations were determined by BCA assay (Thermo Scientific). Proteins boiled in $5 \times$ SDS buffer for $5 \mathrm{~min}$ were subjected to 5\% SDS-PAGE gels, and then transferred to PVDF membranes (Millipore). The membranes were blocked with skim milk and probed with primary antibodies against ACOX1 (Abcam), C/EBP $\beta$ (Cell Signaling Technology), FAS (Cell Signaling technology), ACC (Cell Signaling Technology), HSL (Cell Signaling Technology) and LPL (abclonal, Wuhan, China), respectively. $\beta$-actin (Santa Cruz Biotechnology) served as the loading control. The results were visualized with horseradish peroxidase-conjugated secondary antibodies (KPL, Gaithersburg, MD, USA) and enhanced chemiluminescence.

\section{Plasmid construction, cell culture, transient transfection and analysis}

Based on the Bos taurus ACOX1 gene sequence (accession number: NC_037346.1), five ACOX1 promoter deletion fragments were amplified from the bovine genome via PCR with the primers listed in Supplementary Table 2. Then, the purified PCR products were digested with Kpn I and Xho I (Fermentas, Lithuania) and ligated into the pGL3-Basic vector (Promega). The obtained plasmids were designated ACOX1-P (1-5). Binding site mutations were generated with mutagenic primers (Supplementary Table 2) using overlap-extension PCR. Bovine kidney cells (MDBK) were cultured in DMEM supplemented with $10 \%$ FBS under $5 \% \mathrm{CO}_{2}$ at $37^{\circ} \mathrm{C}$. For luciferase reporter assays, MDBK cells were seeded in 48-well plates. After 12-16 h, the plated cells were transfected with a recombinant plasmid using Lipofectamine 2000 (Invitrogen) according to the methods of Deng et al (Deng et al. 2016).

The potential target site of miR-25-3p, localized in the 3'UTR of ACOX1 mRNA, was predicted by TargetScan. The ACOX1-3'UTR was amplified from bovine cDNA and inserted into the PmeI/XhoI sites of the pmirGLO vector (Promega). Point mutation and deletion in the seed region of the predicted miR-25-3p sites within the ACOX13'UTR were generated using overlap-extension PCR. The corresponding primers are listed in Supplementary Table 3. The luciferase reporter assays could follow a previously described method (Zhang et al. 2018) .

\section{Electrophoretic mobility shift assays}

For electrophoretic mobility shift assays (EMSAs), nuclear proteins (NPs) were extracted from bovine longissimus dorsi muscle by using a Nucleoprotein Extraction Kit (Beyotime). Single-stranded oligonucleotides (Supplementary Table 4) corresponding to the $\mathrm{C} / \mathrm{EBP} \alpha$-binding sites in the ACOX1 promoter were synthesized (Aoke, Wuhan, China) and annealed to obtain double-stranded oligonucleotides. The DNA-binding activity of the C/EBP $\alpha$ protein was detected by using a LightShift Chemiluminescent EMSA Kit (Thermo Scientific) following a previously described method (Deng et al. 2016).

\section{Chromatin immunoprecipitation assay}

Chromatin immunoprecipitation (ChIP) assays were performed by using EZ-ChIP Kit-17-371 (Millipore) 
following a previously described method (Deng et al. 2016). Precleared chromatin was incubated with the C/EBPa antibody (Abcam) or normal rabbit IgG (Abcam) antibody overnight at $4^{\circ} \mathrm{C}$. Purified DNA from the samples and the input controls were analyzed for the presence of ACOX1 promoter sequences containing putative C/EBP $\alpha$ response elements using qRT-PCR. The primers used here are listed in Supplementary Table 5.

\section{Bioinformatics}

Transcription factor binding sites were predicted by using AliBaba2.1 (http://www.gene-regulation.com/) (Wei et al. 2016) and MatInspector (http://www.genomatix.de/ online_help/help_matinspector/matinspector_help.html) (Quandt et al. 1995, Cartharius et al. 2005). The potential target site of miR-25-3p in ACOX1 3'UTR was predicted by TargetScan (http://www.targetscan.org/) (Huang et al. 2016, Wang et al. 2020).

\section{Statistical analysis}

All the results are presented as the means \pm s.D. Student's $t$-test was used for statistical comparisons. A $P$ value of $<0.05$ was considered to be statistically significant. ${ }^{*} P<0.01 ;{ }^{*} P<0.05$; NS, not significant.

\section{Results}

\section{ACOX1 promotes adipogenesis of bovine intramuscular preadipocytes in vitro}

To investigate whether $A C O X 1$ was related to adipogenesis of bovine intramuscular preadipocytes, we isolated bovine intramuscular preadipocytes and performed ACOX1 gain-of-function and loss-offunction experiments. The pCDNA-ACOX1 eukaryotic expression plasmid was constructed and transfected into bovine intramuscular preadipocytes. Following a $24 \mathrm{~h}$ transfection, the cells were induced to undergo adipogenic differentiation, and Oil Red $O$ staining on day 8 showed that over-expression of ACOX1 significantly promoted lipid accumulation (Fig. 1A and $\mathrm{B}$ ). In addition, the concentrations of triglyceride, adenosine 5'-triphosphate (ATP), and ROS were detected after a $24-48 \mathrm{~h}$ transfection. The results showed that over-expression of $A C O X 1$ significant increased levels of triglyceride, whereas significant decreased levels of ATP and ROS (Fig. 1C, D and E). Furthermore, ACOX1 overexpression promoted CCAAT/enhancer binding protein beta $(\mathrm{C} / \mathrm{EBP} \beta)$, fatty acid synthase (FAS), and acetylCoA carboxylase (ACC) expressions, whereas inhibited hormone sensitive lipase (HSL) expression, there was no

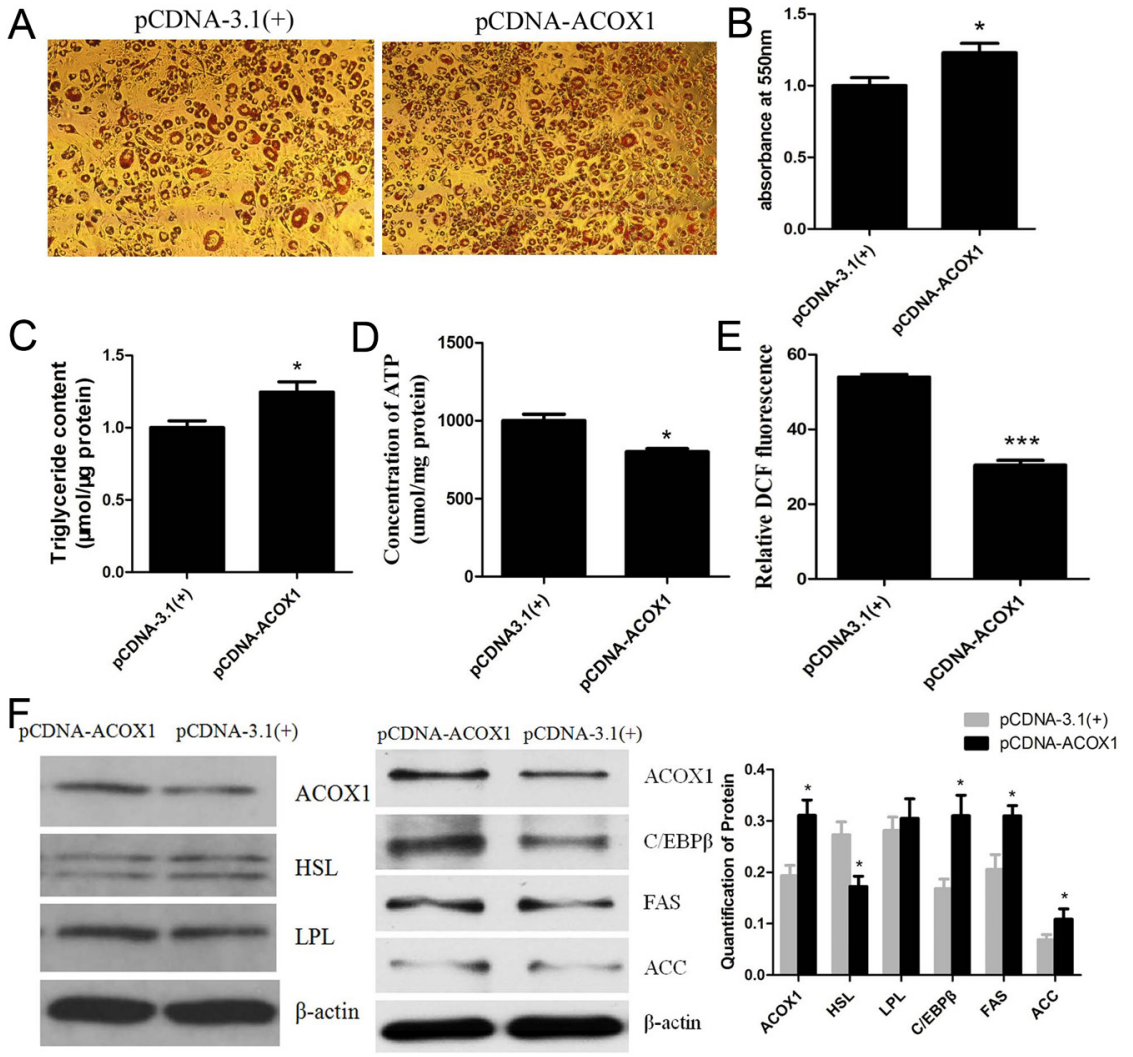

\section{Figure 1}

Overexpression of ACOX1 promotes adipogenesis of bovine intramuscular preadipocytes. The pCDNA-ACOX1 eukaryotic expression plasmid was transfected into bovine intramuscular preadipocytes. Following a $24 \mathrm{~h}$ transfection, the cells were induced to undergo adipogenic differentiation, and stained with Oil Red O on day 8 (A) and lipid drops content was measured by OD $550 \mathrm{~nm}$ (B). After 24-48 $\mathrm{h}$ transfection, the content of triglyceride (C), ATP (D) and Reactive Oxygen Species (ROS) (E) were measured with the commercial kits. The fluorescence of DCF represents the content of ROS. (F) After $48 \mathrm{~h}$ transfection, the expression of HSL, LPL, C/EBP $\beta$, FAS and ACC were detected by Western blotting. $\beta$-actin served as the loading control. pCDNA3.1(+) was used as a negative control. Data were presented as means \pm S.D. $(n \geq 3), * P<0.05$; $\star \star \star * P<0.001$. https://jme.bioscientifica.com https://doi.org/10.1530/JME-20-0250 (c) 2021 The authors Published by Bioscientifica Ltd. Printed in Great Britain

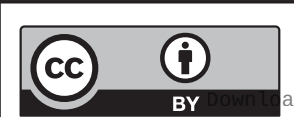

This work is licensed under a Creative Commons Attribution 4.0 International License. 
significant effect on the expression of lipoprotein lipase (LPL), measured by Western blotting (Fig. 1F).

Three different small interference RNAs (siRNA) against ACOX1 were synthesized by RiboBio (Guangzhou, China) and transfected into bovine intramuscular preadipocytes. The efficacy of the siRNA-mediated knockdown was shown in Supplementary Fig. 1. ACOX1 mRNA expression was significantly decreased by Si-ACOX1-2, which was chosen for subsequent experiments. Oil Red $\mathrm{O}$ staining on day 8 showed that Si-ACOX1 significantly diminished the accumulation of lipid droplets (Fig. 2A and B). Triglyceride level was decreased, while ATP and ROS levels were increased by Si-ACOX1 compared with the negative control (NC) siRNA (Fig. 2C, D and E). Moreover, C/EBP $\beta$, FAS, and ACC expressions were suppressed, while HSL and LPL expressions were promoted by Si-ACOX1 (Fig. 2F). Thus, the combined data from gain- and loss-of-function studies consistently demonstrate that $A C O X 1$ promotes adipogenesis of bovine intramuscular preadipocytes.

\section{Isolation and transcriptional activity assay of the bovine ACOX1 promoter}

A $1235 \mathrm{bp}$ fragment of the 5 -flanking region of the bovine ACOX1 gene was obtained from Dabieshan yellow cattle genomic DNA by PCR. Three putative C/EBP $\alpha$ binding sites were predicted within the 5 '-flanking region by AliBaba2.1 and MatInspector (Fig. 3A). To determine whether the isolated 5'-flanking region exhibited promoter activity, this fragment and corresponding fragments with progressive deletions were inserted into a luciferase reporter vector (pGL3-Basic). The plasmids containing the various lengths of the ACOX1 promoter were then transiently transfected into Bovine kidney cells (MDBK). Analyses of luciferase activity revealed that all the deletion vectors have transcriptional activity compared with pGL3-Basic, and ACOX1-P1 (-1272/-38) was the greatest (Fig. 3B). However, the longer fragment showed lower transcriptional activity, suggesting the presence of one or more cis-acting elements between -1049 and -751 bp that can inhibit ACOX1 expression. Moreover, the shorter fragments in ACOX1-P5 to ACOX1-P3 displayed increased transcriptional activity, indicating that the region from -751 to -300 bp contains the cis-acting elements that can induce ACOX1 expression.

\section{ACOX1 transcriptional activity was down-regulated by $\mathrm{C} / \mathrm{EBP} \alpha$}

Five ACOX1 promoter deletion vectors were each co-transfected with pCDNA-C/EBP $\alpha$ into MDBK cells
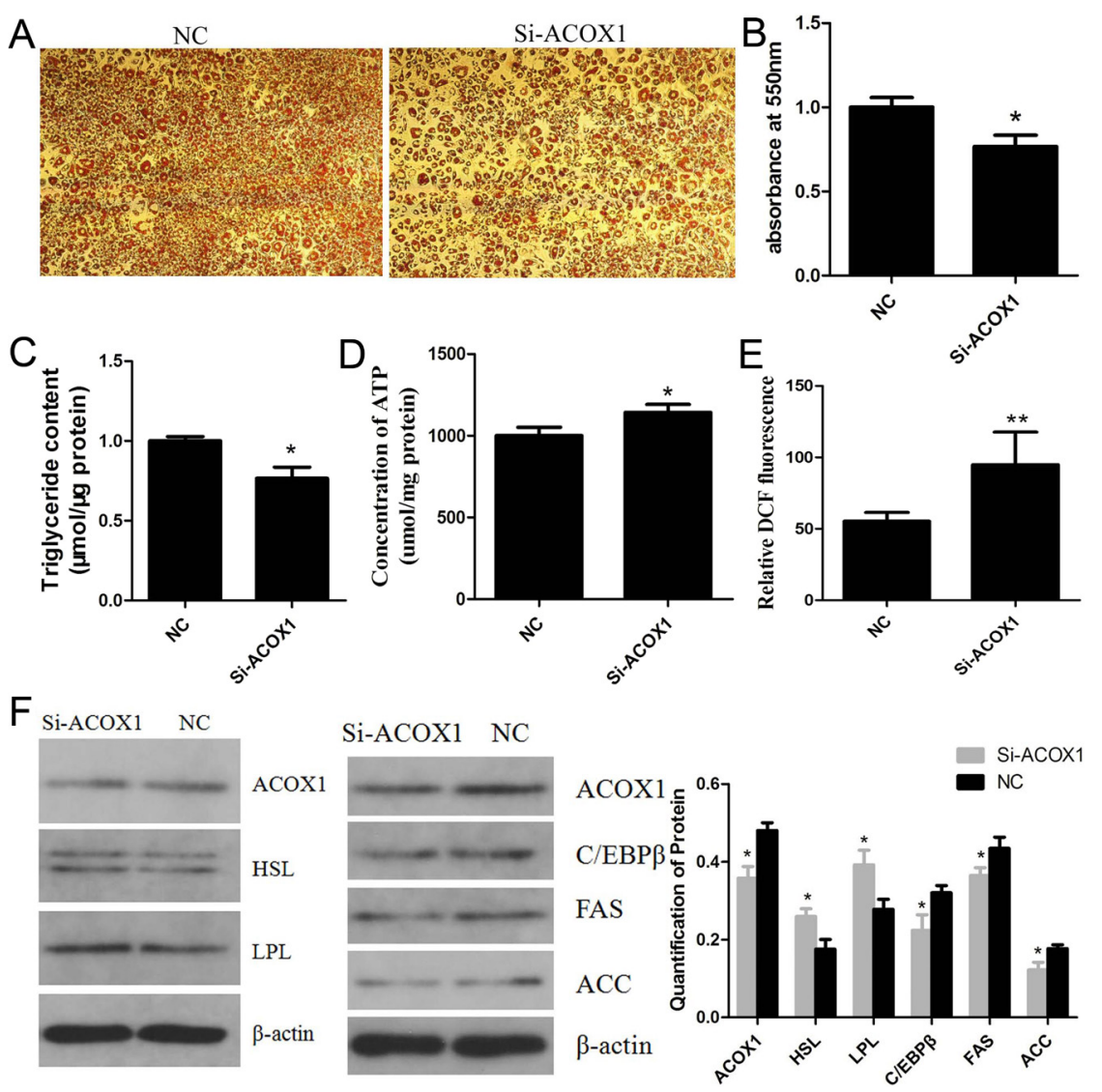

Figure 2

Knockdown of ACOX1 inhibits adipogenesis of bovine intramuscular preadipocytes. small interference RNA (siRNA) against ACOX1 was transfected into bovine intramuscular preadipocytes. Following a $24 \mathrm{~h}$ transfection, the cells were induced to undergo adipogenic differentiation, and stained with Oil Red O on day 8 (A) and lipid drops content was measured by OD $550 \mathrm{~nm}$ (B). After 24-48 $\mathrm{h}$ transfection, the content of triglyceride (C), ATP (D) and Reactive Oxygen Species (ROS) (E) were measured with the commercial kits. The fluorescence of DCF represents the content of ROS. (F) After $48 \mathrm{~h}$ transfection, the expression of HSL, LPL, C/EBP $\beta$, FAS and ACC were detected by Western blotting. $\beta$-actin served as the loading control. NC, negative control. Data were presented as means \pm S.D. $(n \geq 3), * p<0.05 ; * * p<0.01$.

https://jme.bioscientifica.com https://doi.org/10.1530/JME-20-0250 (c) 2021 The authors Published by Bioscientifica Ltd. Printed in Great Britain

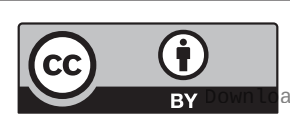

This work is licensed under a Creative Commons Attribution 4.0 International License. ded from Bioscientifica.com at 04/25/2023 11:38:42PM 


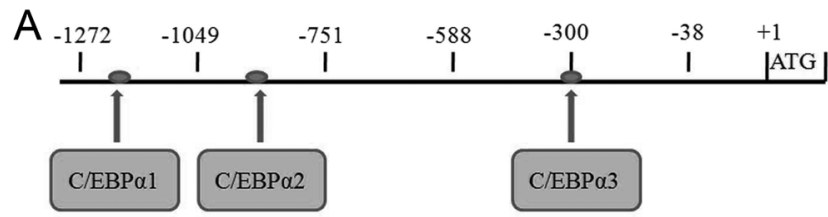

B

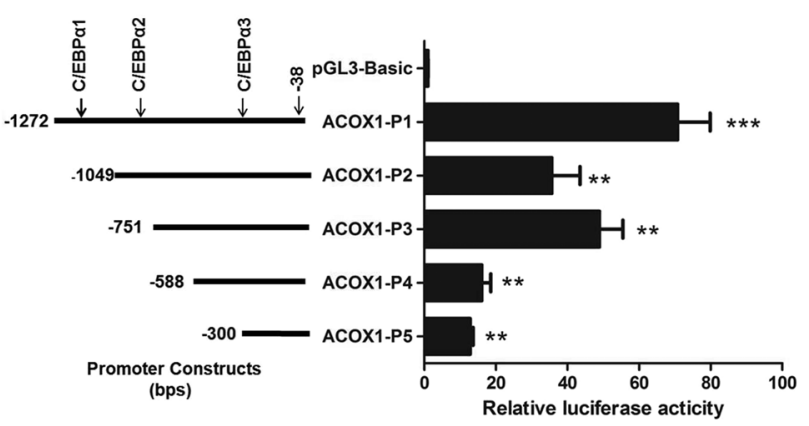

Figure 3

ACOX1 5'-deletion constructs and dual-luciferase reporter assay in Bovine kidney cells (MDBK). (A) Schematic diagram of the C/EBP $\alpha$ binding sites (arrow, solid red circle) in the ACOX1 promoter. The first nucleotide of translation initiation site was assigned as +1 , and the nucleotides were numbered relative to it. (B) Five deletion constructs were transfected into MDBK cells, data were expressed as the ratio of relative activity normalized to $\mathrm{pRL}-\mathrm{TK}$ and then normalized to the activity of pGL3-Basic; they were presented as means \pm S.D. $(n \geq 3), * \star P<0.01 ; * \star * P<0.001$.

to determine the effect of $\mathrm{C} / \mathrm{EBP} \alpha$ on $A C O X 1$ promoter activity. Co-transfection with pCDNA-C/EBP $\alpha$ significantly suppressed $A C O X 1$ promoter transcriptional activity for all of the fragments (Fig. 4A). To determine the functional importance of the $\mathrm{C} / \mathrm{EBP} \alpha$-binding sites, we individually mutated the C/EBP $\alpha$ binding site at -1142 to $-1129 \mathrm{bp}$, -831 to $-826 \mathrm{bp}$, and -303 to $-298 \mathrm{bp}$ by using WT pGL3-ACOX1-P1 as the template (Fig. 4B). A series of mutants of these sites were constructed and transfected or co-transfected with pCDNA-C/EBP $\alpha$ into MDBK cells. Promoter transcriptional activity was significantly increased for mut1, while significantly decreased for mut2 and mut 3 compared with the wild construct (Fig. 4C and D). These results suggested that the first binding site is more likely to be the $\mathrm{C} / \mathrm{EBP} \alpha$ binding site, the second and third sites may also combine with other transcription factors that promote $A C O X 1$ transcription.

To investigate whether $\mathrm{C} / \mathrm{EBP} \alpha$ regulates $A C O X 1$ expression, over-expression and RNA interference experiments of $C / E B P \alpha$ were carried out respectively. Three siRNAs against $C / E B P \alpha$ were synthesized by RiboBio (Guangzhou, China) and transfected into MDBK cells. $C / E B P \alpha$ mRNA expression was significantly decreased by Si-C/EBP $\alpha-1$ (Supplementary Fig. 2), which was chosen for subsequent experiments. pCDNA-C/EBP $\alpha$, pCDNA-3.1(+), $\mathrm{Si}-\mathrm{C} / \mathrm{EBP} \alpha$ and NC were transfected into MDBK cells, respectively. After $48 \mathrm{~h}$ of the transfection, total RNA was isolated. The over-expression of $C / E B P \alpha$ resulted in the significant suppression of $A C O X 1$ expression, while the knockdown of $C / E B P \alpha$ significant increased $A C O X 1$ expression by qRT-PCR (Fig. 4E and F). These results suggested that $\mathrm{C} / \mathrm{EBP} \alpha$ inhibited $A C O X 1$ expression.

\section{Transcription factor C/EBP $\alpha$ binds to ACOX1 promoter both in vitro and in vivo}

To further determine the location of $\mathrm{C} / \mathrm{EBP} \alpha$ binding sites on the ACOX1 promoter region, EMSA and ChIP were performed, respectively. EMSA was performed with nuclear proteins extracts from bovine longissimus dorsi muscle, as shown in Fig. 5A, incubation of nuclear extracts with bioprobe1 led to the formation of a DNA-protein complex (lane 2 ). The quantity of the complex was decreased when cold probe was included in the reaction mixture (lane 3) but the complex formed in the presence of mutant cold probe (lane 4). Although, the DNA-protein-antibody complex was not formed after the anti-C/EBP $\alpha$ was added, the quantity of the DNA-protein complex was decreased (lane 5). This may be that the DNA-protein-antibody complex was too large to enter the gel. For the second and third binding sites, the DNA-protein complex was not increased in the mutant cold probe group (lane 4) compared with cold probe group (lane 3), while the quantity of the DNA-protein complex was decreased after the anti-C/EBP $\alpha$ was added (Fig. 5B and C). These results suggested that all of the three binding sites can bind to $\mathrm{C} / \mathrm{EBP} \alpha$ transcription factor in vitro. Meanwhile, these results further indicated that the second and third sites can also bind to other transcription factors.

ChIP analysis was performed in MDBK cells to determine whether $\mathrm{C} / \mathrm{EBP} \alpha$ can bind to the ACOX1 promoter in vivo. Chromatin was immunoprecipitated with $\mathrm{C} / \mathrm{EBP} \alpha$ antibody and DNA fragments of the expected size were used as a template for PCR amplification. qRTPCR was performed using primers specific to the C/EBP $\alpha$ binding sites in the $A C O X 1$ promoter (Supplementary Table 5). Compared with IgG group, all of the C/EBP $\alpha 1$ to 3 groups expression increased significantly (Fig. 5D, E and F). These results confirmed that all of the three binding sites can bind to $\mathrm{C} / \mathrm{EBP} \alpha$ transcription factor in vivo.

\section{miR-25-3p directly targets ACOX1 3'UTR}

To explore the post-transcriptional regulatory mechanisms of the bovine $A C O X 1$ gene, the possible miRNA targets were predicted using TargetScan, and a putative binding site for miR-25-3p was predicted in the 3'UTR of ACOX1 mRNA.

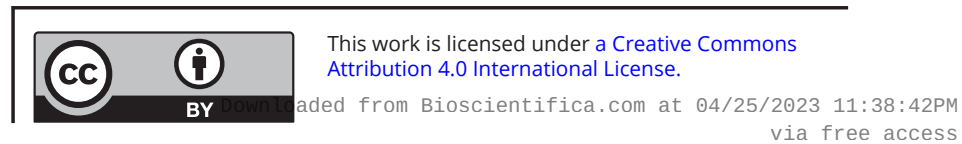


A

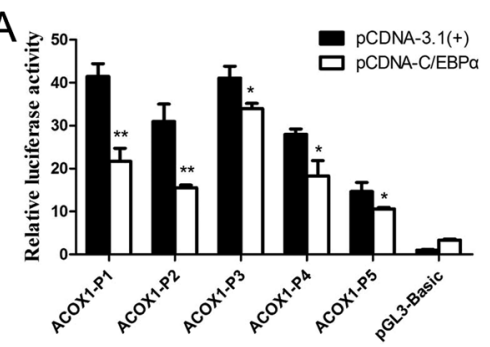

C

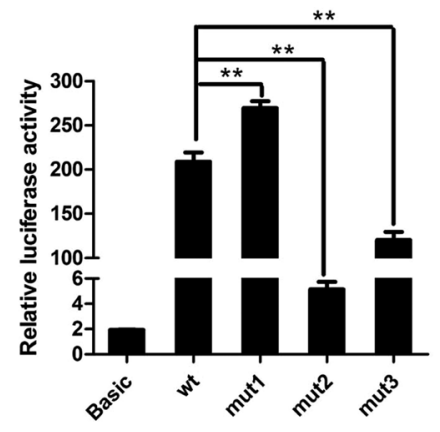

E

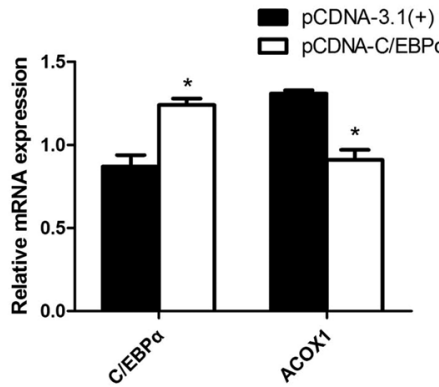

B

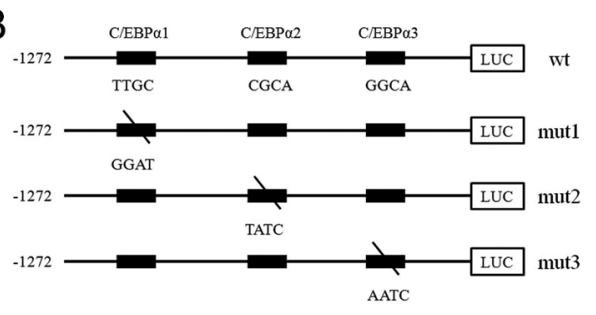

D

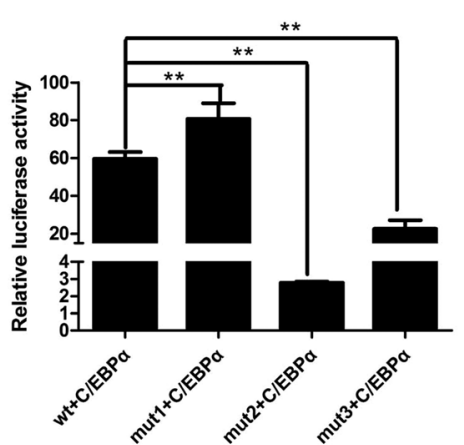

$F$

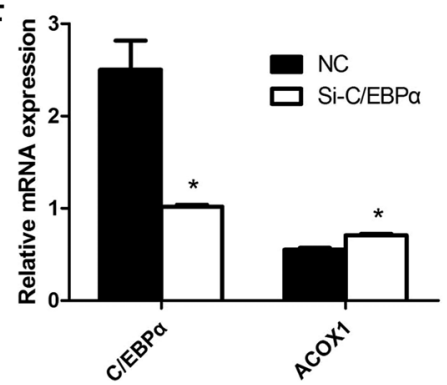

Figure 4

C/EBP $\alpha$ inhibits the transcription of the bovine ACOX1 gene. (A) Five deletion constructs were co-transfected with pCDNA-C/EBP $\alpha$ into MDBK cells. Over-expression of C/EBP $\alpha$ downregulated ACOX1 luciferase activity. (B) The schematic diagram of site-directed mutagenesis in the predicted C/EBP $\alpha$ binding sites in the ACOX1 promoter. ( $C$ and $D) A$ series of mutants of three $\mathrm{C} / \mathrm{EBP} \alpha$ binding sites were constructed and transfected or co-transfected with pCDNA-C/EBP $\alpha$ into MDBK cells. Data were expressed as the ratio of relative activity normalized to $\mathrm{pRL}-\mathrm{TK}$. (E) The pCDNA-C/EBP $\alpha$ eukaryotic expression plasmid was transfected into MDBK cells. After $24 \mathrm{~h}$, C/EBP $\alpha$ and $A C O X 1$ expression was determined by qRT-PCR. (F) Small interference RNA (siRNA) against $C / E B P \alpha$ was transfected into MDBK cells. After $24 \mathrm{~h}, C / E B P \alpha$ and $A C O X 1$ expression was determined by qRT-PCR. NC, negative control. pCDNA-3.1(+) was used as a negative control. Data were presented as means \pm S.D. $(n \geq 3)$, $\star P<0.05 ; * * P<0.01$.
To validate whether miR-25-3p directly targets ACOX1, a luciferase reporter containing a 219 bp fragment from the ACOX1 3'UTR was tested in vitro. Additionally, we generated a mutated and a deleted version of the above mentioned reporter, in which five nucleotides of the predicted binding site were changed or deleted in order to abolish the putative interaction between miR-25-3p and ACOX1 mRNA (Fig. 6A). The ACOX1 3'UTR, mutant and deletion luciferase plasmids were cotransfected with miR-25-3p mimics or NC into MDBK cells. $24 \mathrm{~h}$ after transfection, analyses of luciferase activity revealed that miR-25-3p mimics significantly decreased the luciferase activity of the wild reporter plasmid as compared with mutant and deletion plasmids (Fig. 6B). Meanwhile, miR25-3p mimics significantly decreased the luciferase activity of the wild reporter plasmid as compared with NC, while there was no significant effect on the mutant and deletion plasmids (Fig. 6C). These results revealed that miR-25-3p directly targets the 3'UTR of ACOX1 in vitro.

To directly test the validity of the putative target, we transfected miR-25-3p mimics and miR-25-3p inhibitors into MDBK cells. The results showed that over-expression of miR-25-3p repressed $A C O X 1$ expression, as measured by qRT-PCR $(P<0.01)$ (Fig. 6D) and Western blotting (Fig. $6 \mathrm{~F})$, whereas the knockdown of miR-25-3p derepressed it (Fig. 6E and F). These results demonstrate that the posttranscriptional activity of bovine $A C O X 1$ was downregulated by miR-25-3p.

\section{Discussion}

Intramuscular fat is indicated by the appearance of white flecks or streaks of adipose tissue between bundles of muscle fibers in skeletal muscle (Harper \& Pethick 2004). Intramuscular fat content is one of the main factors for meat quality grades affecting tenderness, flavor, and juiciness of meat and plays an important role in the animal production industry (Lee et al. 2007, Hudson et al. 2015). Compared to other fatty depots, bovine intramuscular fat contains higher levels of polyunsaturated and monounsaturated fatty acids (Troy et al. 2016), so it has higher nutritional value. For this reason, we aimed to investigate the association of ACOX1 gene with intramuscular adipogenesis in this study.

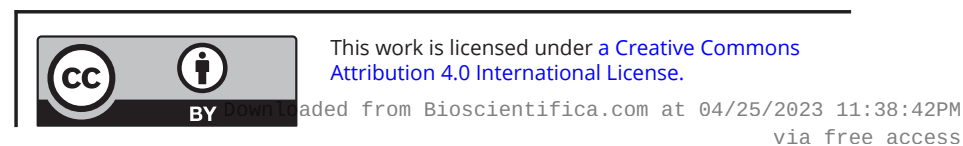


A

$\begin{array}{lllllll}\text { A ane } & 1 & 2 & 3 & 4 & 5 \\ \text { Bio-1 } & + & + & + & + & + \\ \text { Extract } & - & + & + & + & + \\ \text { Wt-1 } & - & - & + & - & - \\ \text { Mut-1 } & - & - & - & + & - \\ \text { Antibody } & - & - & - & - & +\end{array}$

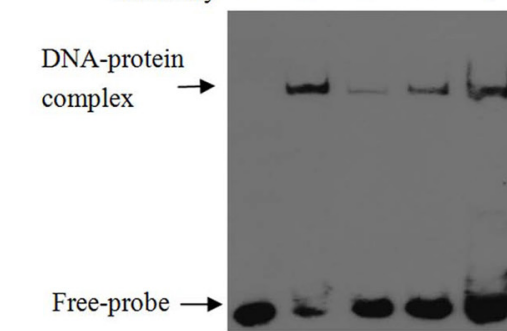

Bio: bio-ACTGTGGTGTTGCAGAAGCCTC-bio Wt: ACTGTGGTGTTGCAGAAGCCTC Mut: ACTGTGGTGggatAGAAGCCTC

C

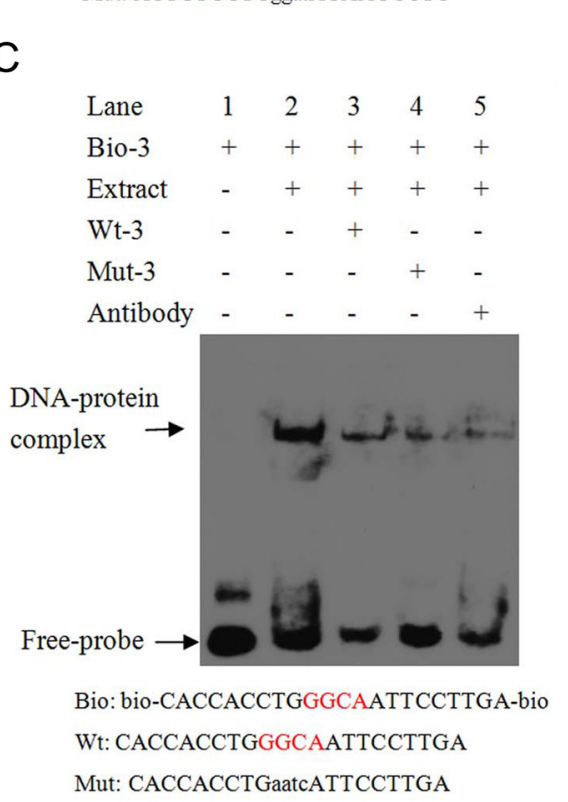

B

$\begin{array}{llllll}\text { Lane } & 1 & 2 & 3 & 4 & 5 \\ \text { Bio-2 } & + & + & + & + & + \\ \text { Extract } & - & + & + & + & + \\ \text { Wt-2 } & - & - & + & - & - \\ \text { Mut-2 } & - & - & - & + & - \\ \text { Antibody } & - & - & - & - & +\end{array}$

Free-probe $\rightarrow$

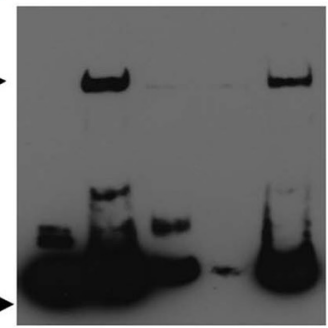

Bio: bio-CCATGGGGTCGCAAGGAGTCGG-bio Wt: CCATGGGGTCGCAAGGAGTCGG Mut: CCATGGGGTtatcAGGAGTCGG

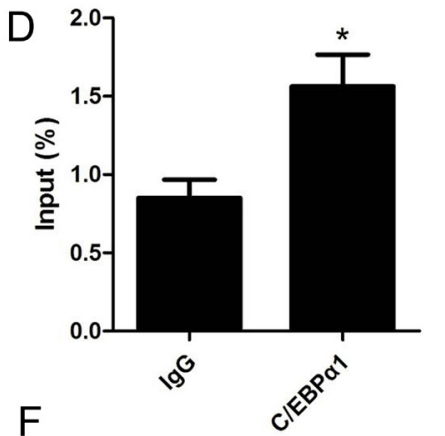

$\mathrm{F}$

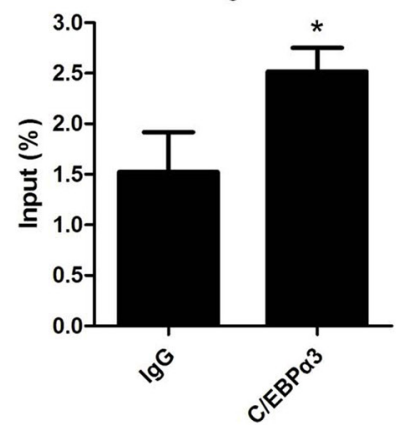

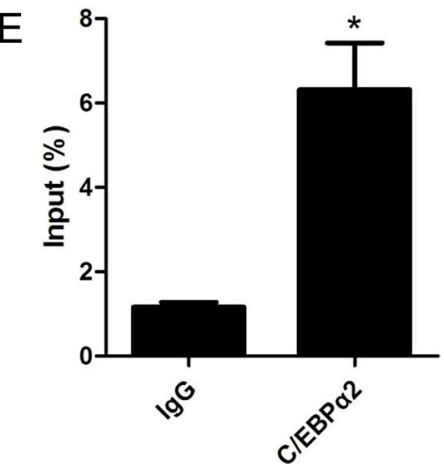

\section{Figure 5}

Binding of C/EBP $\alpha$ to ACOX1 promoter region was analyzed by electrophoretic mobility shift assay (EMSA) and chromatin immunoprecipitation (ChIP). (A, B and C) Probe was incubated with nuclear proteins extract in the absence or presence of a 100-fold excess of various competitor probes (mutant or unlabeled probes) or anti-C/EBP $\alpha$. The specific DNA-protein complex bands were indicated by arrows. The sequences of various probes are shown under the panel. (D, E and F) ChIP assay to analyse C/EBP $\alpha$ binding to the ACOX1 promoter in MDBK cells. DNA isolated from immunoprecipitated materials was amplified using qRT-PCR. Total chromatin was used as the input. Normal rabbit IgG was used as the negative control. A full colour version of this figure is available at https://doi.org/10.1530/JME-20-0250.

The accumulation of intramuscular fat is a dynamic process depending on lipogenesis, lipolysis, adipogenesis, and apoptosis. The disruption of one the these steps deeply affects intramuscular turnover. Acyl-Coenzyme A oxidase 1 (ACOX1) is the first and rate-limiting enzyme in peroxisomal fatty acid $\beta$-oxidation of fatty acids. Previous studies have found that ACOX1 was correlated with the meat quality of livestock (Casas Carrillo et al. 1997, Clop Printed in Great Britain et al. 2003, Yue et al. 2003, Lee et al. 2010, Jiao et al. 2011), while the role of $A C O X 1$ in intramuscular adipogenesis of beef cattle was not clear. In the present study, we performed gain-of-function and loss-of-function experiments in bovine intramuscular preadipocytes to investigate whether ACOX1 was a regulator of intramuscular adipogenesis. Taken together, the data showed that ACOX1 promoted lipid accumulation of bovine 
A

A $A C O X 13$ 'UTR

bta-miR-25

mut- $A C O X 13^{\prime} \mathrm{UTR}$ del- $A C O X 1$ 3'UTR

B

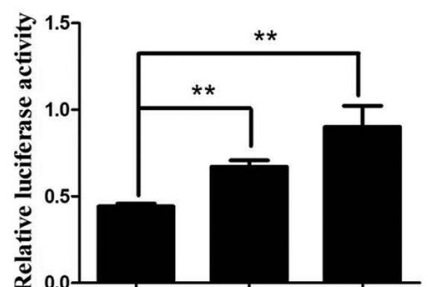

D

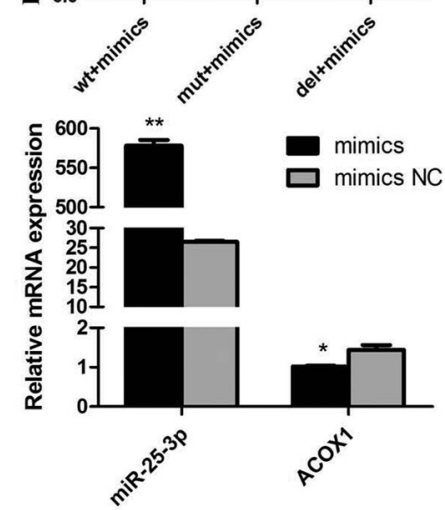

$F$

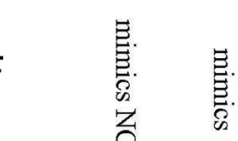

E

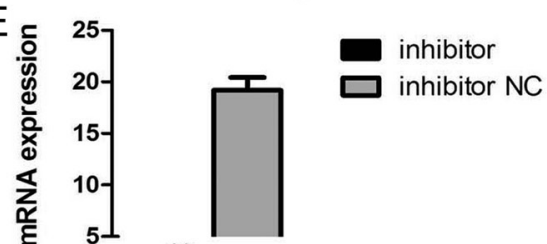

5'-AGAUGUGUUUUACAAGUGCAAUU-3'<smiles>C=CC(=C)C(=C)C(=C)C(=C)C=C</smiles>

'-AGUCUGGCUCUGUUCACGUUAC-5'

5'-AGAUGUGUUUUACAAGGATCCUU-3'

5'-AGAUGUGUUUUACAAG |

C
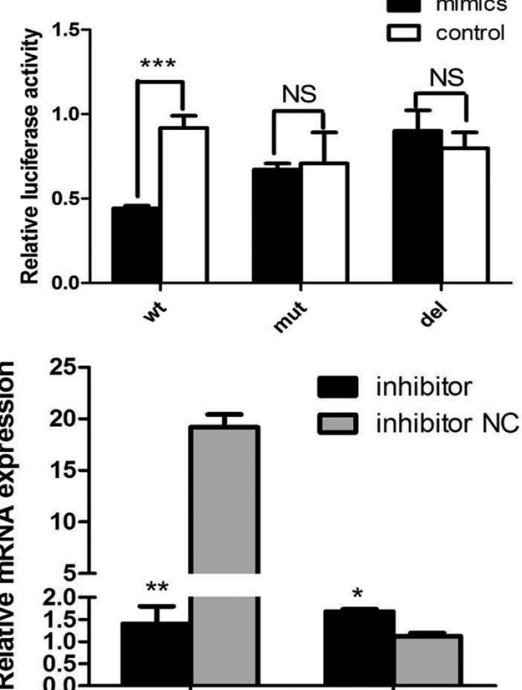

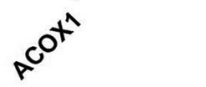

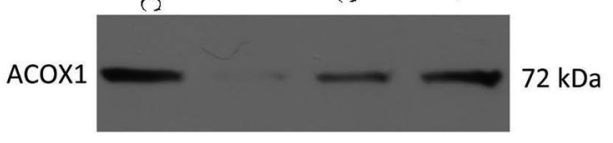

$\beta$-Actin

\begin{abstract}
Figure 6
miR-25-3p directly targets the 3'UTR of ACOX1. (A) Sit-directed mutation and deletion of miR-25-3p target site in the ACOX1 3'UTR. (B and C) Dual luciferase reporter assay. ACOX1 3'UTR, mutant plasmid and deletion plasmid were transfected or co-transfected with miR-25-3p mimics/NC, respectively, into MDBK cells, dual luciferase activities were measured from cell lysates $(24 \mathrm{~h}$ after transfection). miR-25-3p mimics/NC or inhibitor/NC were, respectively, transfected into MDBK cells. After $48 \mathrm{~h}, \mathrm{ACOX} 1$ and miR-25-3p mRNA expression were detected by qRT-PCR (D, E) and ACOX1 protein expression was detected by Western blotting (F). NC, negative control (miR-239b-5p of Caenorhabditis elegans). $\beta$-actin served as the loading control. Data were presented as means \pm S.D. $(n \geq 3), * P<0.05$; $* * P<0.01 ; * * * P<0.001 ;$ NS, not significant.
\end{abstract}

intramuscular preadipocytes. The level of triglyceride was increased by ACOX1, while levels of ATP and ROS were reduced. Meanwhile, Western blotting results showed that the expressions of adipogenic differentiation gene $(C / E B P \beta)$ and fatty acid synthesis genes (FAS and ACC) were induced by $A C O X 1$, while lipolysis genes (LPL and $H S L$ ) expressions were inhibited. These data indicated that ACOX1 promotes adipogenesis of bovine intramuscular preadipocytes in terms of phenotype, gene expression and cell contents.

To further understand the transcriptional regulatory mechanism of $A C O X 1$, we analyzed the $5^{\prime}$-flanking region of bovine ACOX1 gene via AliBaba2.1 and MatInspector. Bioinformatic analysis revealed that there were three potential $\mathrm{C} / \mathrm{EBP} \alpha$ transcription factor binding sites, located at -1142 to $-1129 \mathrm{bp},-831$ to $-826 \mathrm{bp}$, and -303 to $-298 \mathrm{bp}$, respectively. Thus, five fragments of 5 '-flanking sequences of bovine ACOX1 gene were isolated. Subsequently, a series of experiments, including dual luciferase, site-directed mutagenesis, EMSA, ChIP and qRT-PCR assays, confirmed that C/EBP $\alpha$ suppressed transcription of bovine $A C O X 1$ gene via binding to three $\mathrm{C} / \mathrm{EBP} \alpha$ binding sites in the $A C O X 1$ promoter.

CCAAT-enhancer binding protein (C/EBP), a member of the basic leucine zipper (bZIP) transcription factor family, is named for its ability to bind to CCAAT sequences on many gene promoters (Landschulz et al. 1988). It is a family of transcription factors that include $\mathrm{C} / \mathrm{EBP} \alpha$,

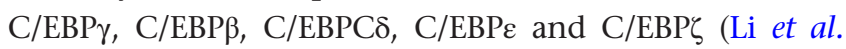
2004). Among them, C/EBP $\alpha, C / E B P \beta$ and $C / E B P C \delta$ are involved in regulating adipocyte differentiation. In addition to PPAR $\gamma, \mathrm{C} / \mathrm{EBP} \alpha$ is the most important factor for regulating lipid deposition and adipocyte differentiation, and its key role is mainly manifested in

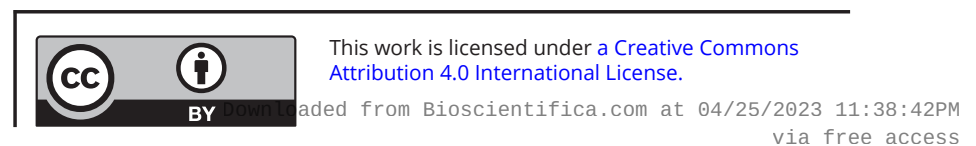


the terminal differentiation stage of adipocytes. During terminal differentiation, $\mathrm{C} / \mathrm{EBP} \alpha$ is induced by $\mathrm{C} / \mathrm{EBP} \beta$ and $\mathrm{C} / \mathrm{EBPC}$, and once expressed, it is activated and maintained by its own C/EBP effector domain (Christy et al. 1991).

Numerous studies have demonstrated that many fatspecific genes promoter have C/EBP effector domain that can be activated by C/EBP $\alpha$ (Macdougald \& Lane 1995). For instance, $\mathrm{C} / \mathrm{EBP} \alpha$ could induce PPAR $\gamma$ expression by identifying the C/EBP effector domain of the PPAR promoter (Wu et al. 1999), and C/EBP $\alpha$ may act as a positive regulator binding to fat mass and obesity associated gene (FTO) promoter and activates the gene transcription (Ren et al. 2014). Meanwhile, previous studies have suggested that $\mathrm{C} / \mathrm{EBP} \alpha$, acted as the transcription factor, could regulate many genes expression. For example, $\mathrm{C} / \mathrm{EBP} \alpha$ regulates transcription of human fructose-1,6bisphosphatase (FBP1) gene via binding to the two overlapping $\mathrm{C} / \mathrm{EBP} \alpha$ binding sites located at nucleotide -228/-208 (Wattanavanitchakorn et al. 2018), C/EBP $\alpha$ binding to the human polo-like kinase 1 (PLK1) promoter results in suppressed PLK1 expression (Dasgupta et al. 2017). Furthermore, there were two C/EBP $\alpha$ binding sites in the chicken cytochrome P450 (CYP) 2D49 promoter, and over-expression of $\mathrm{C} / \mathrm{EBP} \alpha$ significantly upregulated CYP2D49 transcription (Yang et al. 2014). In this study, we identified that $\mathrm{C} / \mathrm{EBP} \alpha$ binds to the ACOX1 promoter region and suppressed its transcription activity.

miRNAs are endogenous, small ( $\sim 22$ nucleotides), and single-stranded noncoding RNAs. The role of different miRNAs in biological systems is well established. They are generally regarded as negative regulators of gene expression, as they bind to the 3'UTR of messengerRNAs (mRNAs), leading to mRNA degradation and/or suppression of mRNA translation (Bartel 2004, Carthew \& Sontheimer 2009, Malan-Mueller et al. 2013). Previously, we have reported that miR-25-3p could reduce the level of triglyceride and increased the levels of ATP and ROS, this was exactly contrary to what ACOX1 does (Zhang et al. 2018). Therefore, we speculated that ACOX1 might be regulated by miR-25-3p. First, we searched for potential miRNAs of bovine ACOX1 gene via TargetScan. Fortunately, the 3'UTR of ACOX1 contained a seven nucleotides perfect match site complementary to the miR-25-3p seed region (Fig. 6A). Then, the dual luciferase reporter assay demonstrated that ACOX1 was a direct target of miR-25-3p, shown by the steady decrease luciferase activity of the wt vector; but not the mutant and deletion form (Fig. 6B and C). Meanwhile, qRT-PCR and Western blotting results showed that the expression of ACOX1 was inhibited by the miR-25-3p mimics, Printed in Great Britain and that this inhibition was reversed by the miR-25-3p inhibitors (Fig. 6D, E and F). These results suggested that the post-transcriptional activity of ACOX1 was suppressed by miR-25-3p.

In conclusion, our results demonstrate that ACOX1 gene acts as a positive regulator of the adipogenesis of bovine intramuscular preadipocytes. Moreover, the transcriptional and post-transcriptional activity of $A C O X 1$ was regulated by C/EBP $\alpha$ and miR-25-3p, respectively.

\section{Supplementary materials}

This is linked to the online version of the paper at https://doi.org/10.1530/ JME-20-0250.

\section{Declaration of interest}

The authors declare that there is no conflict of interest that could be perceived as prejudicing the impartiality of the research reported.

\section{Funding}

This research was supported by the Science Foundation Project of Hubei Academy of Agricultural Sciences (2019NKYJJ04), China Postdoctoral Science Foundation (2017M610465), National Key Research Development Program of China (2017YFD0502000), Hubei Key Projects of Technical Innovation (2019ABA084) and Hubei Agricultural Science and Technology Innovation Action Project (2018skjcx05).

\section{References}

Baarine M, Andreoletti P, Athias A, Nury T, Zarrouk A, Ragot K, Vejux A, Riedinger JM, Kattan Z, Bessede G, et al. 2012 Evidence of oxidative stress in very long chain fatty acid-treated oligodendrocytes and potentialization of ros production using rna interference-directed knockdown of abcd1 and acox1 peroxisomal proteins. Neuroscience 213 1-18. (https://doi.org/10.1016/j.neuroscience.2012.03.058)

Bartel DP 2004 MicroRNAs: genomics, biogenesis, mechanism, and function. Cell 116 281-297. (https://doi.org/10.1016/S00928674(04)00045-5)

Cartharius K, Frech K, Grote K, Klocke B, Haltmeier M, Klingenhoff A, Frisch M, Bayerlein M \& Werner T 2005 MatInspector and beyond: promoter analysis based on transcription factor binding sites. Bioinformatics 21 2933-2942. (https://doi.org/10.1093/ bioinformatics/bti473)

Carthew RW \& Sontheimer EJ 2009 Origins and mechanisms of miRNAs and siRNAs. Cell 136 642-655. (https://doi.org/10.1016/j. cell.2009.01.035)

Casas Carrillo E, Prill Adams A, Price SG, Clutter AC \& Kirkpatrick BW 1997 Mapping genomic regions associated with growth rate in pigs. Journal of Animal Science 75 2047-2053. (https://doi. org/10.2527/1997.7582047x)

Christy RJ, Kaestner KH, Geiman DE \& Lane MD 1991 CCAAT enhancer binding-protein gene promoter-binding of nuclear factors during differentiation of 3T3-L1 preadipocytes. PNAS $\mathbf{8 8}$ 2593-2597. (https://doi.org/10.1073/pnas.88.6.2593)

Clop A, Ovilo C, Perez-Enciso M, Cercos A, Tomas A, Fernandez A, Coll A, Folch JM, Barragan C, Diaz I, et al. 2003 Detection of QTL affecting fatty acid composition in the pig. Mammalian Genome 14 650-656. (https://doi.org/10.1007/s00335-002-2210-7) 
Dasgupta N, Thakur BK, Ta A, Das S, Banik G \& Das S 2017 Polo-like kinase 1 expression is suppressed by CCAAT/enhancer-binding protein $\alpha$ to mediate colon carcinoma cell differentiation and apoptosis. Biochimica et Biophysica Acta: General Subjects 1861 1777-1787. (https://doi.org/10.1016/j.bbagen.2017.03.015)

Deng B, Zhang F, Chen K, Wen JH, Huang HJ, Liu W, Ye SQ, Wang LX, Yang Y, Gong P, et al. 2016 MyoD promotes porcine PPARgamma gene expression through an E-box and a MyoD-binding site in the PPARgamma promoter region. Cell and Tissue Research 365 381-391. (https://doi.org/10.1007/s00441-016-2380-3)

Harper GS \& Pethick DW 2004 How might marbling begin? Australian Journal of Experimental Agriculture 44 653-662. (https://doi. org/10.1071/ea02114)

Huang C, Geng JN, Wei XJ, Zhang RR \& Jiang SW 2016 MiR-144-3p regulates osteogenic differentiation and proliferation of murine mesenchymal stem cells by specifically targeting Smad4. FEBS Letters 590 795-807. (https://doi.org/10.1002/1873-3468.12112)

Hudson NJ, Reverter A, Greenwood PL, Guo B, Cafe LM \& Dalrymple BP 2015 Longitudinal muscle gene expression patterns associated with differential intramuscular fat in cattle. Animal 9 650-659. (https:// doi.org/10.1017/S1751731114002754)

Jiao Y, Zan LS, Liu YF \& Wang HB 2011 Molecular characterization, polymorphism of the ACOX1 gene and association with ultrasound traits in Bos taurus. Genetics and Molecular Research 10 1948-1957. (https://doi.org/10.4238/vol10-3gmr1036)

Kunau WH, Dommes V \& Schulz H 1995 Beta-oxidation of fatty acids in mitochondria, peroxisomes, and bacteria: a century of continued progress. Progress in Lipid Research 34 267-342. (https://doi. org/10.1016/0163-7827(95)00011-9)

Landschulz WH, Johnson PF, Adashi EY, Graves BJ \& McKnight SL 1988 Isolation of a recombinant copy of the gene encoding C/EBP. Genes and Development 2 786-800. (https://doi.org/10.1101/gad.2.7.786)

Lee SH, Park EW, Cho YM, Kim SK, Lee JH, Jeon JT, Lee CS, Im SK, Oh SJ, Thompson JM, et al. 2007 Identification of differentially expressed genes related to intramuscular fat development in the early and late fattening stages of hanwoo steers. Journal of Biochemistry and Molecular Biology 40 757-764. (https://doi.org/10.5483/BMBRep.2007.40.5.757)

Lee JK, Cho YM \& Lee JH 2010 Association of bovine CSRP3 and ACOX1 genes with carcass and meat quality traits. Korean Journal of Agricultural Science 37 231-238. (uci: G704-SER000011699.2010.37.2.005)

Li YX, Tharappel JC, Cooper S, Glenn M, Glauert HP \& Spear BT 2000 Expression of the hydrogen peroxide-generating enzyme fatty acyl CoA oxidase activates NF-kappa B. DNA and Cell Biology 19 113-120. (https://doi.org/10.1089/104454900314627)

Li RN, Strohmeyer R, Liang Z, Lue LF \& Rogers J 2004 CCAAT/enhancer binding protein delta (C/EBP delta) expression and elevation in Alzheimer's disease. Neurobiology of Aging 25 991-999. (https://doi. org/10.1016/j.neurobiolaging.2003.10.016)

Macdougald OA \& Lane MD 1995 Transcriptional regulation of geneexpression during adipocyte differentiation. Annual Review of Biochemistry 64 345-373. (https://doi.org/10.1146/annurev. bi.64.070195.002021)

Malan-Mueller S, Hemmings SMJ \& Seedat S 2013 Big effects of small RNAs: a review of microRNAs in anxiety. Molecular Neurobiology 47 726-739. (https://doi.org/10.1007/s12035-012-8374-6)

Morais S, Knoll-Gellida A, Andre M, Barthe C \& Babin PJ 2007 Conserved expression of alternative splicing variants of peroxisomal acyl-CoA oxidase 1 in vertebrates and developmental and nutritional regulation in fish. Physiological Genomics 28 239-252. (https://doi. org/10.1152/physiolgenomics.00136.2006)

Nohammer C, El-Shabrawi Y, Schauer S, Hiden M, Berger J, Forss-Petter S, Winter E, Eferl R, Zechner R \& Hoefler G 2000 cDNA cloning and

analysis of tissue-specific expression of mouse peroxisomal straightchain acyl-CoA oxidase. European Journal of Biochemistry 267 1254-1260. (https://doi.org/10.1046/j.1432-1327.2000.01128.x)

Quandt K, Frech K, Karas H, Wingender E \& Werner T 1995 MatInd and MatInspector: new fast and versatile tools for detection of consensus matches in nucleotide sequence data. Nucleic Acids Research 23 4878-4884. (https://doi.org/10.1093/nar/23.23.4878)

Ren W, Guo JJ, Jiang F, Lu J, Ding Y, Li AM, Liang XB \& Jia WP 2014 CCAAT/enhancer-binding protein $\alpha$ is a crucial regulator of human fat mass and obesity associated gene transcription and expression. BioMed Research International 2014 406909. (https://doi. org/10.1155/2014/406909)

Tong QY, Ge CJ \& Zheng SH 2016 Expression of PPARalpha and Acox1 in rats with alcoholic fatty liver disease. Acta Medicinae Universitatis Scientiae et Technologiae Huazhong 45 288-291. (https://doi. org/10.3870/j.issn.1672-0741.2016.03.010)

Troy DJ, Tiwari BK \& Joo ST 2016 Health implications of beef intramuscular fat consumption. Korean Journal for Food Science of Animal Resources 36 577-582. (https://doi.org/10.5851/kosfa.2016.36.5.577)

Wang JH, Yao Y, Wang KL, Li J, Chu T \& Shen H 2020 MicroRNA$148 \mathrm{a}-3 \mathrm{p}$ alleviates high glucose-induced diabetic retinopathy by targeting TGFB2 and FGF2. Acta Diabetologica 57 1435-1443. (https://doi.org/10.1007/s00592-020-01569-7)

Wattanavanitchakorn S, Rojvirat P, Chavalit T, MacDonald MJ \& Jitrapakdee S 2018 CCAAT-enhancer binding protein- $\alpha(\mathrm{C} / \mathrm{EBP} \alpha)$ and hepatocyte nuclear factor $4 \alpha(\mathrm{HNF} 4 \alpha)$ regulate expression of the human fructose-1,6-bisphosphatase 1 (FBP1) gene in human hepatocellular carcinoma HepG2 cells. PLoS ONE 13 e0194252. (https://doi.org/10.1371/journal.pone.0194252)

Wei XJ, Cheng XY, Peng YD, Zheng R, Chai J \& Jiang SW 2016 STAT5a promotes the transcription of mature mmu-miR-135a in 3T3-L1 cells by binding to both miR-135a-1 and miR-135a-2 promoter elements. International Journal of Biochemistry and Cell Biology 77 109-119. (https://doi.org/10.1016/j.biocel.2016.06.003)

Wu ZD, Rosen ED, Brun R, Hauser S, Adelmant G, Troy AE, McKeon C, Darlington GJ \& Spiegelman BM 1999 Cross-regulation of C/EBP alpha and PPAR gamma controls the transcriptional pathway of adipogenesis and insulin sensitivity. Molecular Cell 3 151-158. (https://doi.org/10.1016/s1097-2765(00)80306-8)

Yang Q, Tang SL, Dong LF, Chen QM, Liu X, Jiang J \& Deng YQ 2014 Transcriptional regulation of chicken cytochrome P450 2D49 basal expression by CCAAT/enhancer-binding protein $\alpha$ and hepatocyte nuclear factor $4 \alpha$. FEBS Journal 281 1379-1392. (https://doi. org/10.1111/febs.12710)

Yue G, Schroffel J, Moser G, Bartenschlager H, Reiner G \& Geldermann H 2003 Linkage and QTL mapping for Sus scrofa chromosome 12. Journal of Animal Breeding and Genetics 120 95-102. (https://doi.org/10.1046/j.0931-2668.2003.00429.x)

Zeng J, Deng SW, Wang YP, Li P, Tang L \& Pang YF 2017 Specific inhibition of acyl-CoA oxidase- 1 by an acetylenic acid improves hepatic lipid and reactive oxygen species (ROS) metabolism in Rats fed a high fat diet. Journal of Biological Chemistry 292 3800-3809. (https://doi.org/10.1074/jbc.M116.763532)

Zhang F, Chen K, Tao H, Kang TT, Xiong Q, Zeng QH, Liu Y, Jiang SW \& Chen MX 2018 miR-25-3p, positively regulated by transcription factor AP-2 alpha, regulates the metabolism of C2C12 cells by targeting Akt1. International Journal of Molecular Sciences 19773. (https://doi.org/10.3390/ijms19030773)

Zuo B, Yang H, Lei MG, Li FE, Deng CY, Jiang SW \& Xiong YZ 2007 Association of the polymorphism in GYS1 and ACOX1 genes with meat quality traits in pigs. Animal 1 1243-1248. (https://doi. org/10.1017/S1751731107000523)

Received in final form 17 December 2020

Accepted 22 January 2021

Accepted Manuscript published online 28 January 2021

https://jme.bioscientifica.com https://doi.org/10.1530/JME-20-0250 (c) 2021 The authors Published by Bioscientifica Ltd. Printed in Great Britain

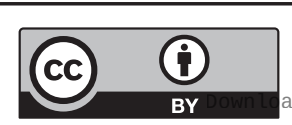

This work is licensed under a Creative Commons Attribution 4.0 International License. ded from Bioscientifica.com at 04/25/2023 11:38:42PM 